demonstrating intolerance of RVAD removal. We therefore exchanged her paracorporeal Levitronix RVAD for a Thoratec intracorporeal VAD (Pleasanton, Calif). ${ }^{2}$ Postoperatively, she recovered from MSOF and was discharged from the hospital on postoperative day 53.

Repeat RVAD turndown 4 months later showed functional RV recovery, and the patient's Thoratec RVAD was successfully explanted. One month later, she was at home, doing well, and enjoying normal daily activities.

\section{DISCUSSION}

RV failure from acute RV infarction is associated with high morbidity and mortality rates. Early revascularization and RVAD implantation as a bridge to recovery allowed our patients the time and opportunity for RV recovery.

Experience with the use of RVADs to treat isolated RV failure from acute myocardial infarction is limited. RV failure requiring RVAD placement has been a notable complication after LVAD placement. Isolated RV failure in postcardiotomy patients has been described in few studies, suggesting that RV function in this setting is salvageable with early mechanical support. ${ }^{3}$ Longer duration of RVAD support is becoming more feasible as more RVADs are designed to be implantable and portable, such as the Thoratec intracorporeal VAD. This device allowed patient 2 to continue rehabilitation on an outpatient basis, improving her overall quality of life.

Weaning protocols for VADs are varied and yet to be standardized. $^{4,5}$ Our protocol involves echocardiography during an RVAD turndown, and if hemodynamic parameters are maintained, we elect to explant the RVAD. In our experience, hemodynamic stability during RVAD turndown reliably predicts explantation success.

\section{CONCLUSIONS}

RVADs can be used effectively in patients who experience isolated RV infarction secondary to dissection of the right coronary artery. Our experience suggests that patients may successfully undergo RVAD placement as a bridge to recovery or heart transplantation. RVADs should be considered early in the care of patients with isolated RV failure as a result of acute myocardial infarction.

We thank Mary E. Knatterud, $\mathrm{PhD}$, for editorial assistance.

\section{References}

1. John R, Liao K, Leitz K, Kamdar F, Colvin-Adams M, Boyle A. Experience with the Levitronix CentriMag circulatory support system as a bridge to decision in patients with refractory acute cardiogenic shock and multisystem organ failure. J Thorac Cardiovasc Surg. 2007;134:351-8.

2. Farrar D, Reichenbach SH, Rossi SA, Weidman JR. Development of an intracorporeal Thoratec ventricular assist device for univentricular or biventricular support. ASIAO J. 2000;46:351-3.

3. Moazami N, Pasque M, Moon M. Mechanical support for isolated right ventricular failure in patients after cardiotomy. J Heart Lung Transpl. 2004;23: 1371-5.

4. Delgado D, Rao V, Miriuka S. Explantation of a mechanical assist device: assessment of myocardial recovery. J Card Surg. 2004;17:47-50.

5. Slaughter M, Sobieski M, Koening S, Pappas P, Tatooles A, Silver M. Left ventricular device weaning: hemodynamic response and relationship to stroke volume and rate reduction protocols. ASIAO J. 2006;52:228-33.

\title{
Successful cardiac transplant after Berlin Heart bridge in a single ventricle heart: Use of aortopulmonary shunt as a supplementary source of pulmonary blood flow
}

\author{
F. Bennett Pearce, MD, ${ }^{\mathrm{a}}$ James K. Kirklin, MD, ${ }^{\mathrm{b}}$ William L. Holman, MD, ${ }^{\mathrm{b}}$ Cindy S. Barrett, MD, ${ }^{\mathrm{a}}$ Robb L. Romp, MD, ${ }^{\mathrm{a}}$ \\ and Yung R. Lau, MD, ${ }^{\mathrm{a}}$ Birmingham, Ala
}

Pulsatile ventricular assist devices, and in particular the Berlin Heart Excor infant ventricular assist device (Berlin Heart; Berlin Heart AG, Berlin, Germany), have rarely been used to support infants and small children with single

From the Divisions of Pediatric Cardiology ${ }^{\mathrm{a}}$ and Cardiothoracic Surgery, ${ }^{\mathrm{b}}$ UAB School of Medicine, Birmingham, Ala.

Received for publication Jan 24, 2008; accepted for publication Feb 7, 2008.

Address for reprints: F. Bennett Pearce, MD, Division of Pediatric Cardiology, NHB

320, 619 19th St South, Birmingham, AL 35249-6852 (E-mail: pearce@uab.edu). J Thorac Cardiovasc Surg 2009;137:e40-2

$0022-5223 / \$ 36.00$

Copyright (C) 2009 by The American Association for Thoracic Surgery doi:10.1016/j.jtcvs.2008.02.044 ventricle. $^{1,2}$ We report successful cardiac transplantation in an infant with single ventricle supported with a Berlin Heart.

\section{CLINICAL SUMMARY}

A 15-month-old boy with the diagnosis of $\{$ S,D,D $\}$ double-outlet right ventricle, mitral valve atresia, D-malposition of the great vessels, status-post pulmonary artery band in infancy, and poor systemic ventricular function was referred for transplant evaluation. A catheterization performed at the referral institution 3 months before admission documented mean central venous pressure of $25 \mathrm{~mm} \mathrm{Hg}$, poor 
systemic ventricular function with severe atrioventricular valve regurgitation, and bilateral iliac vein thrombosis.

At the time of arrival he was intubated, receiving infusions of dopamine, epinephrine, and milrinone. His examination was notable for anasarca. Vitals signs on admission were as follows: pulse 135 beats/min, blood pressure $75 / 54 \mathrm{~mm}$ $\mathrm{Hg}$, weight $8.3 \mathrm{~kg}$, and systemic oxygen saturation $87 \%$. Laboratory data demonstrated arterial lactate $2 \mu \mathrm{Mol} / \mathrm{l}$, blood urea nitrogen $40 \mathrm{mg} / \mathrm{dL}$, creatinine $0.8 \mathrm{mg} / \mathrm{dL}$, total bilirubin $3.4 \mathrm{mg} / \mathrm{dL}$, aspartate aminotransferase 1453 $\mu \mathrm{Mol} / \mathrm{l}$, and gamma glutamyl transferase $58 \mu \mathrm{Mol} / \mathrm{l}$.

Because of worsening circulatory and end-organ status, extracorporeal membrane oxygenation (ECMO) was initiated on hospital day 16 . Cannulas, $8 \mathrm{~F}$ arterial and $12 \mathrm{~F}$ venous, were placed in the right common carotid artery and right internal jugular vein, respectively. Cannula positions were confirmed with echocardiography. ECMO flow was adjusted to maintain mixed venous oxygen saturation $75 \%$ to $80 \%$. The patient responded with decreasing liver enzymes, increased urine output, partial resolution of edema, and reduction in central venous pressure to 14 to $16 \mathrm{~mm} \mathrm{Hg}$.

After 3 days of ECMO support complicated by progressive hemolysis, a $25-\mathrm{mL}$ Berlin Heart left ventricular assist device was implanted. At operation, the patient was converted from ECMO to cardiopulmonary bypass. For Berlin Heart implantation the pulmonary artery was ligated distal to the pulmonary artery band and a 5-mm polytetrafluoroethylene shunt (Gore-Tex shunt; W. L. Gore \& Associates, Inc, Flagstaff, Ariz) was placed from the ascending aorta to the right pulmonary artery. Cannulas were placed in the right atrium and ascending aorta inferior to the shunt (Figure 1).

The right internal jugular vein and the right common carotid artery were repaired. At the conclusion of the procedure, systemic arterial saturation was $60 \%$ to $65 \%$. The pulmonary artery ligature was removed, the pulmonary band being left in place as a second pathway for pulmonary blood flow. Systemic arterial saturation was $75 \%$ to $80 \%$ after this. Delayed sternal closure was done 48 hours later.

Berlin Heart support was maintained for 7 weeks until a suitable organ was available. The patient was extubated. He received physical therapy and enteral feeds. He was active, maintaining oxygen saturations of $65 \%$ to $85 \%$ with supplemental oxygen. End-organ function normalized. Echocardiography confirmed antegrade pulmonary blood flow and flow through the polytetrafluoroethylene shunt.

Anticoagulation was started on postoperative day 2. Unfractionated heparin, warfarin, clopidogrel, and aspirin were used. Heparin was discontinued when the international normalized ratio reached the target range of 2.5 to 3.5. There were no thrombotic or hemorrhagic complications.

Transplantation was carried out with a recipient/donor weight ratio of 0.92 . The panel reactive antibody was 0 . After discontinuation of cardiopulmonary bypass, the pul-

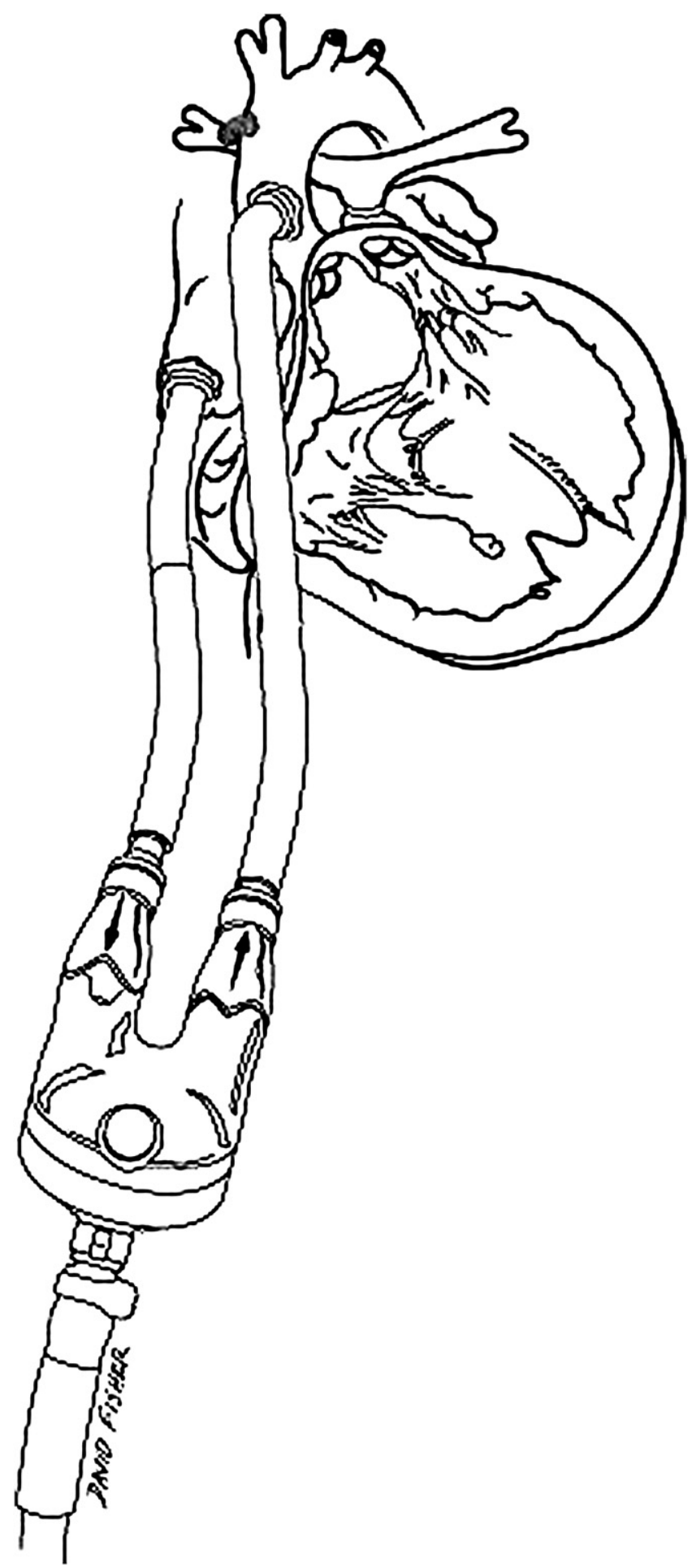

FIGURE 1. Berlin Heart and shunt placement.

monary artery pressure was one half the systemic pressure. Transesophageal study showed dilation of the right ventricle with focal reduction in right ventricular systolic function. The central venous pressure was 19 to $20 \mathrm{~mm} \mathrm{Hg}$ for the first 24 hours postoperatively during support with nitric 
oxide, nitroglycerin, and prostaglandin infusions. Right ventricular function on echocardiography improved commensurate with decrease central venous pressure to the 12 $\mathrm{mm} \mathrm{Hg}$ range and extubation on day 8 .

Catheterization with biopsy was done on postoperative day 35. The reconstructed right internal jugular vein was used for vascular access. The right heart pressures were mildly elevated and histologic examination demonstrated no rejection. The patient was discharged several days later.

The patient remains well without graft dysfunction or rejection 2 months after transplantation.

\section{DISCUSSION}

The Berlin Heart provides long-term support, consuming fewer blood products and allowing extubation and reversal of debilitation not possible with ECMO. ${ }^{3,4}$ Use of the Berlin Heart in infants with single ventricle physiology has been rarely reported with no reports of successful transplantation to hospital discharge. ${ }^{1,2}$ Provision of systemic and pulmonary circulation with a single ventricular assist device is challenging. The technique we describe worked well in our case and may be useful in similar situations.

\section{References}

1. Chu MW, Sharma K, Tchervenkov CI, Jutras LF, Lavoie J, Shemie SD, et al. Berlin Heart ventricular assist device in a child with hypoplastic left heart syndrome. Ann Thorac Surg. 2007;83:1179-81.

2. Nathan M, Baird C, Fynn-Thompson F, Almond C, Thiagarajan R, Laussen P, et al. Successful implantation of a Berlin Heart biventricular assist device in a failing single ventricle. J Thorac Cardiovasc Surg. 2006;131:1407-8.

3. Stiller B, Hetzer R, Weng Y, Hummel M, Hennig E, Nagdyman N, et al. Heart transplantation in children after mechanical circulatory support with pulsatile pneumatic assist device. J Heart Lung Transplant. 2003;22:1201-8.

4. Stiller B, Lemmer J, Merkle F, Alexi-Meskishvili V, Weng Y, Hubler M, et al. Consumption of blood products during mechanical circulatory support in children: comparison between ECMO and a pulsatile ventricular assist device. Intensive Care Med. 2004;30:1814-20.

\title{
Modified perfusion technique for patients with renal cell carcinoma infiltrating the inferior vena cava
}

\author{
Gianluigi Bisleri, MD, ${ }^{\mathrm{a}}$ Paolo Piccoli, MD, ${ }^{\mathrm{a}}$ Sergio Cosciani Cunico, MD, ${ }^{\mathrm{b}}$ and Claudio Muneretto, MD, ${ }^{\mathrm{a}}$ Brescia, Italy
}

The surgical removal of renal cell carcinoma with thrombus extension in the inferior vena cava (IVC) and right atrium has been extensively described by means of a combined abdominal and thoracic approach with the aid of cardiopulmonary bypass and deep hypothermic circulatory arrest. $^{1-3}$

In an effort to further reduce the potential complications of such a perfusion technique (especially in terms of postoperative bleeding), we developed a simple modification of the circulatory support to provide continuous antegrade perfusion of the supra-aortic vessels during systemic circulatory arrest with moderate hypothermia.

\section{CLINICAL SUMMARY}

A 71-year-old woman was admitted to the Division of Urology at the University of Brescia Medical School after prolonged hematuria. Multislice abdominal computed to-

\footnotetext{
From the Divisions of Cardiac Surgery ${ }^{\mathrm{a}}$ and Urology, ${ }^{\mathrm{b}}$ University of Brescia Medical School, Brescia, Italy.

Received for publication Jan 31, 2008; accepted for publication Feb 10, 2008.

Address for reprints: Gianluigi Bisleri, MD, Cardiochirurgia SSVD-Spedali Civili,

P.le Spedali Civili, 1, 25123 Brescia, Italy (E-mail: gianluigi.bisleri@gmail.com).

J Thorac Cardiovasc Surg 2009;137:e42-4

$0022-5223 / \$ 36.00$

Copyright (c) 2009 by The American Association for Thoracic Surgery

doi:10.1016/j.jtcvs.2008.02.046
}

mography evaluation evidenced a huge neoplastic plurifocal mass in the left kidney, with a neoplastic thrombus infiltrating the main left renal vein and the IVC close to the suprahepatic veins. The diameter of the mass in the IVC at its maximum was approximately $6 \mathrm{~cm}$ (Figure 1). An echoDoppler evaluation of the IVC confirmed a cephalad extension of the mass just below the origin of the suprahepatic veins (with an overall distance from the right atrium of $3 \mathrm{~cm}$ ). Bone scintigraphy, multislice thoracic, and cerebral computed tomography scans did not detect any metastatic diffusion of the disease. The patient was therefore scheduled to undergo a combined procedure of left nephrectomy and IVC thrombus evacuation under cardiopulmonary bypass with hypothermic arrest.

After exposure of the kidney, its vascular structures, and the IVC up to the diaphragm, conventional sternotomy and pericardial opening were performed, exposing the aortic arch and supra-aortic branches up to the left subclavian artery. The ascending aorta was cannulated in the conventional fashion while a cannulation of both the right atrium and the superior vena cava (with a Y-connection to the main venous line) was carried out (Figure 2). A vent line was also placed in the left ventricle through the right superior pulmonary vein. Once the patient was on full cardiopulmonary bypass, systemic cooling to $25^{\circ} \mathrm{C}$ was achieved, the ascending aorta 